
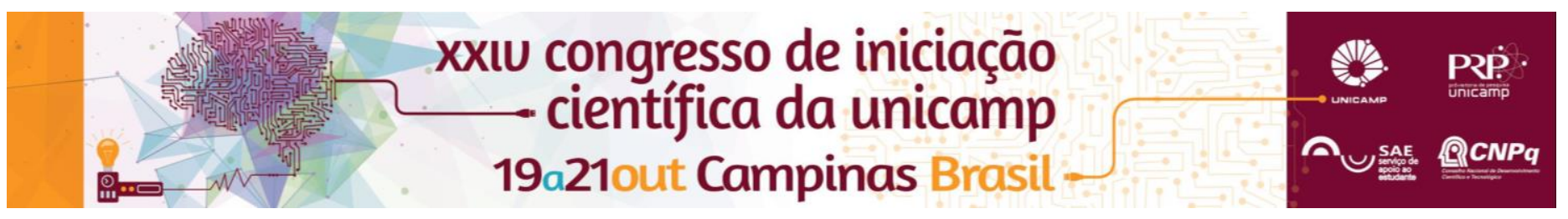

\title{
Fabrication of Microestrutured Polymer Optical Fibers
}

\author{
Thiago H. R. Marques*, Alex J. Salvador, Cristiano M. B. Cordeiro
}

\begin{abstract}
In this work we present an overview about microestructured polymer optical fibers (mPOFs) fabrication. This is a relatively new branch of research, which have attracted attention due to its advantages when compered to traditional glasses fibers, such as high functionalization possibilities and freedom of design. There are few groups around the world that are capable to produce mPOFs, including our group.
\end{abstract}

\section{Key words:}

Optical fiber, microstructured polymer optical fiber, photonic crystal fiber

\section{Introduction}

Polymer optical fibers have taken place in the last decade as a powerful device with great applicability in sensing [1]. The interest in polymer fibers lies in their flexibility, low coast and huge geometry possibilities.

In the Physics Institute of UNICAMP, at the Specialty Optical Fiber Laboratory (LaFE), we have the only dedicated polymer fiber pulling tower in Brazil. In collaboration with others institutions we already shown the first inscription of high-quality Bragg gratins in microstructured polymer optical fiber (mPOF) [2] and the production and study of polymer capillaries as hydrostatic pressure sensors with elevated sensibility [3].

\section{Results and Discussion}

The basic idea of the production process is quite simple, it begins with a microscope version of the fiber, called preform, which is drilled by a Computer Numerical Control (CNC) device [4]. After that, the preform, typically with a $70 \mathrm{~mm}$ diameter is fixed in the tower, heated until $200^{\circ} \mathrm{C}$ and, then, pulled. However, producing the fiber directly from the preform causes great changes in the final structures in comparison with the one designed, it happens due to the physical properties of Polymers, such as viscosity and Young modulus. Because of that the preform is first pulled in a cane with $12-16 \mathrm{~mm}$ of diameter, which can then be directly pulled to a fiber. Typical dimensions for a POF varies from $100 \mu \mathrm{m}$ to $1.5 \mathrm{~mm}$ - large diameters fibers are one of the advantages of polymers fibers over silica ones. During the pulling process the fiber's diameter is controlled using a relation of the ratio between feed and pulling velocities and the ratio of initial and final diameters. In fig 1.A. present a schematization of pulling process, in fig 1.B a preform with hexagonal structure on focus.

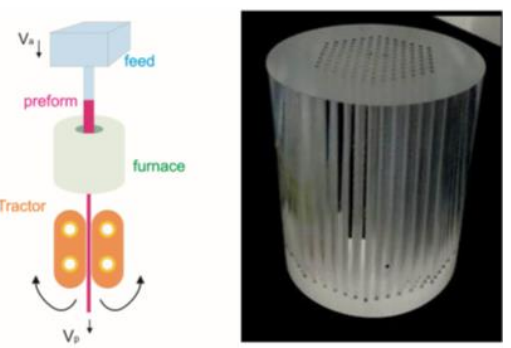

Figure 1. Drawing schema

In fig. 2 we present some manufactured mPOF structures produced, most of them very difficult to obtain using glass.

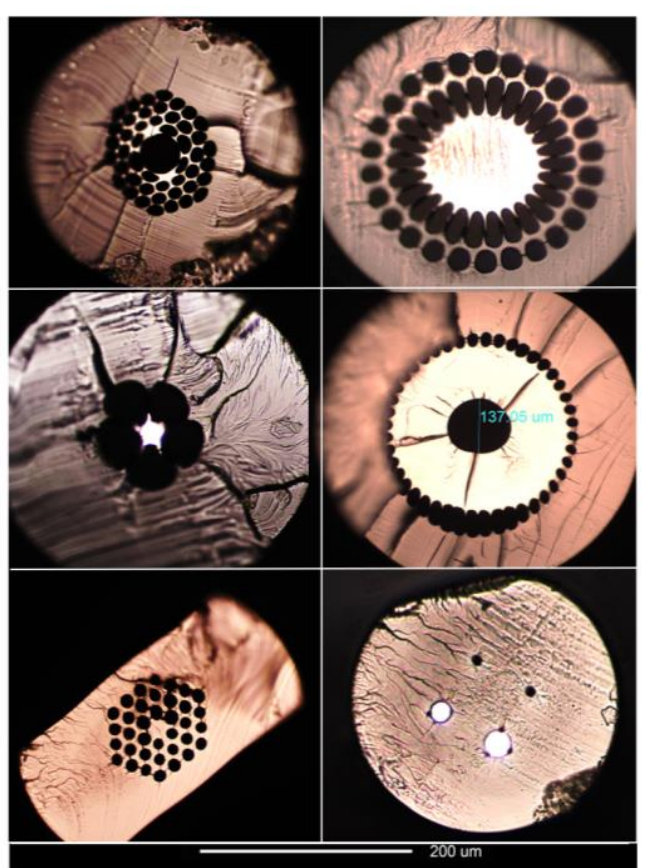

Figure 2. Fiber cross section optical pictures of some produced samples

Beyond microstructured and capillaries fibers multimaterial and functionalized optical fibers can also be produced as seen in figure $\mathbf{2}$ - a fiber with Zeonex $(\AA$ core and a PMMA cladding.

\section{Conclusions}

Even polymers fibers being limited to short distances applications due to its high optical loss some of its advantages make mPOFs a powerful platform for optical sensing. Exploratory fiber geometries are being studied.

\section{Acknowledgement}

We would like to thank FINEP and Itech for the support and all LaFE, especially José Aparecido for technical help.

1 LARGE, Maryanne C. J. et al. Microstructured polymer optical fibers. Sydney: Springer, 2008. 248 p.

2 Oliveira, R.; Bilro, L.; Marques, T. H. R.; Napierala, M .; Tenderenda, T.; Mergo, P.; Nasilowski, T; Cordeiro, C. M. B.; e Nogueira, R. IEEE Photonics tecnology letters, 2016, 28, 6

3 Gouveia, M. A,; Avila, P. D.; Marques, T. H. R.; Torres, C.; e Cordeiro, C. M. B.; Optics Express, 2015, 23, 8.

4 Salvador, A. J; Marques, T. H. R.; Cordeiro, C. M.; XXIV Congresso de Iniciação Científica da Unicamp, 2016. 